\title{
Una aproximación al amor en la filosofía de Baruch Spinoza
}

DANILO TAPIA

Pontificia Universidad Católica del Perú

Resumen:

El artículo analiza la noción de amor en la filosofía de Spinoza a través del Tratado de la reforma del entendimiento, el Tratado breve y la Ética. El amor en Spinoza debe contextualizarse en su fenomenología crítica de los afectos y su teoría del conocimiento. Así es posible mostrar que, para Spinoza, cómo se ama -activa o pasivamente- es más importante que una distinción normativa entre objetos de amor correctos o incorrectos. Esta interpretación sobre el amor en Spinoza es coherente con las premisas éticas y el monismo ontológico de su filosofía, y con su afirmación de que el amor es también una actividad de la Sustancia.

Palabras clave:

Spinoza, amor, ética, afectos, psicología

\section{Abstract:}

This paper offers an analysis of Spinoza's concept of love based on the Treatise on the Emendation of the Intellect, the Short Treatise on God and the Ethics. Spinoza's concept of love must be understood within his critical phenomenology of affects and his theory of knowledge. Thus understood, Spinoza's concept of love entails that how we love - actively or passively - is more important than any normative distinction among objects of love. This reading of Spinoza's concept of love is compatible with his ethical premises and his ontological monism, and with his understanding of love as an activity of the Substance.

Keywords:

Spinoza, love, ethics, affects, psychology 


\section{§1. Introducción}

Es un lugar común reconocer que el proyecto ético de Spinoza exhibe notables afinidades con la filosofía antigua y helenística', entre las cuales se encuentra el carácter eudaimonista de su proyecto. Para Spinoza, el télos de la vida humana es el logro de la felicidad verdadera, para lo cual es de crucial importancia el control activo sobre las pasiones. Podemos afirmar que el ambicioso proyecto de Spinoza, al igual que el de las filosofías antiguas y helenísticas, articula una comprensión ontológica de la totalidad con un análisis psicológico y fenomenológico del alma y de los afectos, teniendo siempre como objetivo final el proponer un camino para la liberación de la verdadera esencia racional, activa y social del sujeto humano. Por ello, dentro del proyecto de Spinoza, el análisis del deseo y el tema del amor ocupan un lugar central, al igual que en varias filosofías antiguas y helenísticas.

El presente trabajo constituye una aproximación —-tentativa y provisionalal tema del amor en la filosofía de Spinoza. Intentaremos rastrear la noción de amor de Spinoza a través del Tratado de la reforma del entendimiento (TRE), el Tratado breve (TB) y la Ética demostrada según el orden geométrico $(E)^{2}$. En nuestro recorrido analizaremos la función del amor dentro de la filosofía de Spinoza, contextualizándola en relación con su ontología, su psicología y su ética. El análisis y la contextualización mencionados nos revelarán que la filosofía del amor de Spinoza no nos propone un ascetismo o una negación total de los afectos corporales o materiales, ni tampoco un ascenso purificador del deseo desde lo sensible hacia lo inteligible, o desde lo corporal a lo espiritual. La filosofía del amor de Spinoza — sobre todo, en

1 Acerca de las afinidades y diferencias entre el proyecto filosófico de Spinoza y la filosofía estoica, véase DeBrabander 2007; Miller 2015. Sobre la relación entre el naturalismo estoico y el de Spinoza véase Hoyos 2012. Por su parte, Vardoulakis (2020) propone una lectura epicúrea del pensamiento político de Spinoza centrándose en el Tratado Teológico-Político.

2 Utilizamos la edición de Atilano Domínguez para Alianza Editorial del Tratado de la reforma del entendimiento (Spinoza 1988) y citamos de acuerdo a parágrafo (§) y página de la edición mencionada (ej.: TRE §12, 79). Utilizamos la edición de Atilano Domínguez para Alianza Editorial del Tratado breve (Spinoza 1990) y citamos de acuerdo a parte, capítulo y página de la edición mencionada (ej.: TB II, 5, 111). En cuanto a la Ética, utilizamos la edición de Atilano Domínguez (Spinoza 2000) y citamos de acuerdo a Libro, Proposición, Definición (D), Escolio (E), Corolario (C) o Capítulo (Cap.) y página de la edición mencionada, según sea el caso (ej.: EII, D 3, 77). 
su desarrollo definitivo en la Ética - se basa en un análisis fenomenológico y psicológico de los afectos, articulado con una teoría del conocimiento. Spinoza analiza el afecto del amor a partir de su vinculación con los grados del conocimiento, siendo el amor de acuerdo a la imaginación fuente de diversos problemas psicológicos, éticos y sociales. Para Spinoza, el progreso en el conocimiento constituye un progreso en nuestra capacidad de tener afectos activos basados en ideas adecuadas. En última instancia, esto nos lleva a un reconocimiento gozoso, tanto intelectual como afectivo, de nuestra pertenencia a la Naturaleza: el amor intelectual a Dios. De acuerdo Spinoza, tal sería el camino para alcanzar la libertad y la virtud.

\section{§2. Amor y eudaimonismo en el Tratado de la reforma del entendimiento}

El título del Tratado de la reforma del entendimiento podría anticipar objetivos estrictamente epistemológicos. Sin embargo, en sus primeras páginas, Spinoza señala como su preocupación fundamental la búsqueda de un bien verdadero, eterno, comunicable y estable para la vida humana que brinde una "alegría continua y suprema" (TRE §1, 75). Los seres humanos solemos vivir asumiendo que el sumo bien radica en las riquezas, la fama y los honores y el placer ${ }^{3}$. Buscar estos supuestos "bienes" nos distrae y consume nuestras vidas. Spinoza testimonia que encontró necesario abandonar estos "bienes inciertos" para poder reflexionar y encontrar un remedio que permita curar al deseo humano $(\operatorname{TRE} \S 7,77)^{4}$. En efecto, los deseos erróneos

3 Por su parte, en Ética Nicomáquea I 5 1095b15-1096a10, Aristóteles distingue entre cuatro modos de vida, según las diferentes creencias ordinarias acerca del sumo bien: la vida voluptuosa del placer, la vida política de los honores, la vida de negocios y la riqueza y, por último, la vida contemplativa.

4 Las analogías entre filosofía y medicina y entre virtud del alma y salud del cuerpo eran usuales entre epicúreos y estoicos. Epicuro advierte que "Vana es la palabra de aquel filósofo que no remedia ninguna dolencia del hombre. Pues así como ningún beneficio hay de la medicina que no expulsa las enfermedades del cuerpo, tampoco lo hay de la filosofía, si no expulsa la dolencia del alma" (Epicuro, Us. 221). En espíritu similar va la admonición del estoico romano Musonio Rufo en sus Disertaciones: "Pues igual que no resulta ningún beneficio del discurso médico si no conduce a la salud del cuerpo humano, así tampoco, si el filósofo sostiene o enseña a alguien un discurso, no resulta de ello ningún beneficio a menos que conduzca a la virtud del alma humana" (Musonio Rufo 1995, V, 12, 10-20). Sobre la noción estoica y epicúrea 
constituyen prácticamente una enfermedad: la búsqueda desmedida de riqueza, honores y placer puede inclusive causar la muerte (TRE §7, 77).

Sin embargo, Spinoza no propone un ascetismo radical o una extirpación estoica de los deseos. El deseo por dinero, honores o placer no es en sí mismo perjudicial, el error consiste en concebir esos bienes como fines en sí mismos y no como lo que son: medios que pueden servir para alcanzar un fin5. En la filosofía de Spinoza no hay definición absoluta de "bien" y "mal": "bien y mal sólo se dicen en sentido relativo, de forma que una y la misma cosa se puede decir buena y mala en sentidos distintos, lo mismo que lo perfecto y lo imperfecto"(TRE §12, 79).

En el Tratado de la reforma del entendimiento la principal causa de los males del ser humano radicaría en la naturaleza de los objetos que perseguimos como si fuesen el fin último. Aquí Spinoza introduce al amor como concepto para describir el accionar del ser humano que persigue lo que considera un sumo bien: "Me parecía a mí que todos estos males tenían su origen en haber puesto toda la dicha o desdicha en la calidad del objeto al que nos adherimos por el amor." Así, los males humanos acontecen "cuando se aman cosas que pueden perecer" — como el placer, la fama o la riquezateniendo como consecuencia luchas, tristeza, pereza, envidia, temor y odio (TRE §9, 78). El objeto correcto para nuestro amor es Dios. Esta afirmación será sostenida, mutatis mutandis, por Spinoza a través de toda su filosofía del amor: "Por el contrario, el amor hacia una cosa eterna e infinita apacienta el alma con una alegría totalmente pura y libre de tristeza, lo cual es muy de desear y digno de ser buscado con todas nuestras fuerzas" (TRE §10, 78).

Pese a lo anterior, en la filosofía de Spinoza, el amor hacia la Sustancia eterna e infinita no podría implicar una "superación" del amor a las "cosas terrenas" o un ascetismo negador de todo afecto dirigido a las "cosas materiales"

de la filosofía como medicina o terapia que cura a los humanos del sufrimiento causado por sus deseos patológicos (y patogénicos), véase Nussbaum 2012.

5 "(...) comprendí que el conseguir dinero, placer y gloria estorba, en la medida en que se los busca por sí mismos y no como medios para otras cosas. Pues, si se buscan como medios, ya tienen una medida y no estorban en absoluto, sino que, por el contrario, ayudarán mucho al fin por el que se buscan (...)" (TRE §11, 79). 
juzgadas como "malas". Tales perspectivas metafísicamente dualistas y moralmente absolutistas no son coherentes con las premisas de Spinoza, tanto ontológicas - la Naturaleza-Sustancia-Dios no es un ente trascendente al mundo-y éticas — para Spinoza no hay bien o mal absolutos. Por ende, en la filosofía del amor de Spinoza no estamos ante una reorientación de los afectos terrenos hacia un objeto erótico ontológica y moralmente superior, ni tampoco un "ascenso" desde lo material y corporal hacia lo espiritual y divino según el modelo del eros platónico ${ }^{6}$. Pareciera haber una tensión entre, por un lado, rechazar diferentes tipos de objetos de amor según su valor y, por otro, las premisas ontológicas y éticas de la filosofía de Spinoza. Como veremos, esta tensión será resuelta por Spinoza configurando una fenomenología del afecto amoroso que enfatice el aspecto cognoscitivo del mismo, según la cual lo más importante no será tanto cuál es el objeto amado sino cómo se ama.

\section{§3. El amor en el Tratado breve}

En el Tratado breve, Spinoza afirma enfáticamente que el amor es indispensable para los seres humanos, pues somos por naturaleza débiles y necesitados. Simplemente no podríamos existir si no pudiésemos amar: "de acuerdo a la debilidad de nuestra naturaleza, necesariamente debemos amar algo y unirnos con ello para existir" (TB II, 5, 111). Asimismo, es imposible librarnos del amor porque es un afecto inseparable de la experiencia humana en lo que esta tiene de cognoscitivo. Nuestra esencial capacidad de conocer nos lleva a valorar determinados objetos como buenos y útiles, lo cual nos lleva a amarlos (TB II, 5, 110). En el Tratado breve, Spinoza define al amor en los siguientes términos: “El amor no es nada más que gozar de una cosa y unirse con ella; lo dividiremos según las cualidades de su objeto, ya que el hombre intenta gozar de él y unirse a él" (TB II, 5, 109). El amor se origina en nuestro conocimiento de determinada cosa que juzgamos como buena o excelente y por eso la amamos: "El amor nace, pues, del concepto y del conocimiento que tenemos de una cosa. Y cuanto mayor

6 Sobre la noción platónica de eros véase el discurso de Diotima en Banquete 201d - 212b; también, la palinodia de Sócrates y el mito del auriga en Fedro 242c - 257b. 
y más excelente se demuestre que es la cosa, tanto mayor también es en nosotros el amor" (TB II, 5, 110). Para Spinoza en el Tratado breve el amor por un objeto se sigue de un juicio valorativo positivo sobre ese objeto. Esta evaluación valorativa determina una clasificación de tipos de objetos de amor.

Así, en el Tratado breve, Spinoza distingue entre tres posibles tipos de objetos de amor: a) objetos perecederos en sí mismos; b) objetos imperecederos por su causa; c) objeto imperecedero por su propia fuerza y potencia ${ }^{7}$. A partir de esa distinción entre tipos de objetos de amor, Spinoza buscará establecer cuál de ellos es el más adecuado para los seres humanos.

Los "objetos perecederos" son aquellos que debemos rechazar de plano como objetos de amor. Nuestra débil naturaleza no se fortalece en absoluto si nos unimos a cosas perecederas "dado que ellas mismas son débiles y un cojo no puede sostener a otro" (TB II, 5, 111). Más aún, las cosas perecederas no solamente no ayudan a fortalecer nuestra existencia, son incluso perjudiciales. Si el amor es una "unión" o un "llegar a ser una misma cosa" con la cosa amada entonces "es sin duda miserable aquel que se une con una cosa perecedera". Esta miseria y sufrimiento es producto del hecho de que la cosa amada no está bajo el poder del amante, sino que es una causa exterior de su amor. "Pues, como ésta está fuera de su poder y sujeta a muchos azares, es imposible que, si ella llega a sufrir, pueda él librarse de ello" (TB II, 5, 111). A partir de ello, Spinoza llega a una conclusión próxima a los saberes éticos de la filosofía helenística: "Si quienes aman las cosas perecederas, que aún tienen algún ser, son tan miserables, ¡cuánto no lo serán quienes aman los honores, las riquezas y los placeres, que no tienen en absoluto esencia alguna" (TB II, 5, 111).

7 "Algunos objetos son perecederos en sí mismos; otros son imperecederos por su causa; pero hay un tercero que es eterno e imperecedero exclusivamente por su propia fuerza y potencia. Perecederos son todas las cosas particulares, que no han existido desde todo tiempo o que han recibido un comienzo. Los otros son todos los modos que son, según hemos dicho, causa de los modos particulares. El tercero es Dios o, lo que nosotros consideramos lo mismo, la Verdad" (TB II, 5, 110). 
La segunda clase posible de objetos de amor son los objetos eternos e imperecederos que no lo son por su propia fuerza, sino por ser modos de Dios. De acuerdo con Gerszenzon $(2016,122)$, el segundo tipo de objetos de amor sería todo aquello que Spinoza denomina la natura naturata: la naturaleza entendida como los diversos modos de la Sustancia. Por último, el tercer objeto de amor es Dios. Siempre inmutable, Dios constituye el "único" objeto que debe ser amado y nos salva de caer en la "cloaca de pasiones" que caracteriza al amor por cosas perecederas. Por ello, "Dios es la causa primera y única de todo nuestro bien y un libertador de todos nuestros males" (TB II, 14, 126-127).

Nuevamente Spinoza pareciera plantearnos una concepción del amor en la cual lo central son las características de los objetos amados. Algunos objetos serían intrínsecamente malos como objetos de amor y deberían ser absolutamente evitados. Sin embargo, como ya hemos mencionado, esto entra en cierta tensión con las premisas ontológicas, psicológicas y éticas de Spinoza. ¿Cómo reconciliar el monismo, el determinismo, la neutralidad moral y el no-finalismo del pensamiento ontológico y ético de Spinoza con la afirmación de que existen objetos de amor intrínsecamente malos?

Un camino para resolver esta tensión ${ }^{8}$ se abrirá si tenemos presentes dos elementos ya mencionados. El primero, que el Dios al que se refiere Spinoza no es trascendente, sino es la Sustancia-Dios-Naturaleza (natura naturans);

8 Gerszenzon (2016: 110-113) considera que en el TB y el TRE Spinoza plantea una definición del amor basada en los objetos a los éste que se puede dirigir, definición de la cual se alejaría en la Ética. La lectura de Gerszenzon se opone a una interpretación tradicional, según la cual lo más importante en la filosofía del amor de Spinoza —incluso en la Ética - es amar al tipo correcto de objeto y rechazar al incorrecto. En esa interpretación, el sabio spinoziano renunciaría a cualquier vínculo afectivo con las personas individuales y los objetos materiales para alcanzar la libertad y la actividad afectiva en una comunión mística con "Dios" (Jaquet, Sévérac y Suhamy 2005, 9; Hampshire 1982, 116-121). Así, de acuerdo a Hampshire: “El hombre libre y sabio, por tanto, se siente moralmente indiferente hacia las cosas y personas particulares que le rodean..." (Hampshire 1982, 116). Del otro lado de este debate, intérpretes contemporáneos afirman que la filosofía del amor Spinoza es principalmente una fenomenología de los afectos, cuya conclusión invita a limitar los afectos pasivos promovidos por la imaginación y a promover los afectos activos basados en la razón y en la ciencia intuitiva. En esta lectura, más coherente con la ontología y los presupuestos éticos de Spinoza, el amor intelectual por Dios no constituye un ascetismo o una renuncia al mundo, sino por el contrario, una afirmación gozosa, tanto afectiva como intelectual, de nuestra pertenencia a él. Interpretaciones de este tipo pueden encontrarse en Misrahi 2005, 46-65; Rorty 2009; Bicknell 1998; Gerszenzon 2016. 
el segundo, la importancia de la relación entre conocimiento y afectos en la filosofía de Spinoza. Ya en el Tratado breve es claro que el amor por los modos de Dios tiene necesariamente en su base el amor a Dios. Los modos de Dios dependen ontológicamente de Dios, así como nuestro conocimiento de los modos de Dios depende de nuestro concepto de Dios. Por lo tanto, nuestro amor por los modos de Dios depende también de nuestro amor a Dios. Si usamos correctamente nuestro entendimiento y conocemos a Dios como causa de sus modos, nuestro conocimiento de la perfección de Dios nos llevará a amarlo. Así, para Spinoza nuestro conocimiento correcto y nuestro amor a los modos de Dios puede llevarnos al conocimiento de Dios y al amor de Dios. Dado que Dios contiene "en sí solo toda la perfección, necesariamente debemos amarlo" (TB II, 5, 112).

Como veremos a continuación, Spinoza en la Ética desarrollará su teoría del amor profundizando y relacionando una fenomenología de los afectos con una teoría del conocimiento, que culminará en su noción de un amor intelectual de Dios. Este desarrollo comienza través del libro III, en el cual Spinoza realiza un detallado análisis fenomenológico-crítico del rol de la imaginación —conocimiento del primer género- en la producción de los afectos pasivos. A ello dirigiremos nuestra atención a continuación.

\section{§4. Afectos, imaginación y amor en la Ética}

La definición de amor que plantea Spinoza en el libro III de la Ética es bastante conocida:

En efecto, el amor no es otra cosa que la alegría acompañada de la idea de una causa exterior; y el odio no es otra cosa que la tristeza acompañada de la idea de una causa exterior. Vemos, además, que quien ama, necesariamente se esfuerza por tener presente y conservar la cosa que ama; y, por el contrario, quien odia, se esfuerza por alejar y destruir la cosa que odia ( $E$ III, 13, E, 136-137).

Como es sabido, Spinoza concibe a los afectos primarios de la alegría y la tristeza como cambios hacia una mayor o menor perfección, respectivamente ( $E$ III, 11, E, 134). La alegría y la tristeza consisten respectivamente 
en el incremento o disminución de nuestra potencia para actuar en tanto cuerpos y de pensar en tanto almas ( $E$ III, 37, 151). Ahora bien, esta alegría que es el amor aquí descrito está relacionada a ideas de causas exteriores, las cuales corresponden al acto cognoscitivo de la imaginación. Así, los objetos imaginados pueden aumentar o disminuir la potencia de actuar del cuerpo y de pensar del alma. Por ello el alma tiende a imaginar cosas amadas, pues incrementan su conato ${ }^{9}$.

Ahora bien, pese a que el amor es alegría - aumento de la potencia de actuar y pensar, incremento de la perfección, expansión del conato- su relación con la imaginación ocasionará varias dificultades cuyo análisis requerirá que tomemos en cuenta el aspecto cognoscitivo de la definición de Spinoza del amor. Spinoza se refiere al amor en el libro II de la Ética como un "modo del pensar" (modus cogitandi) ${ }^{10}$ y subraya en la definición que hemos citado que está asociado a ideas ${ }^{11}$. Ahora bien, como ya mencionamos, dado que el amor depende de "la idea de una causa exterior", el funcionamiento de la imaginación es crucial para explicar lo que podríamos denominar "amor pasional", pues la imaginación es la capacidad de representarse las cosas exteriores como imágenes ${ }^{12}$.

En la perspectiva de Spinoza, "imaginación" abarca lo que coloquialmente denominaríamos como tal, pero también incluye a la percepción sensible y al recuerdo, actividades todas que constituyen el primer género del conocimiento. Para Spinoza, imaginación es la capacidad general de

9 Así, de acuerdo a Spinoza, "el alma se esfuerza cuanto puede en imaginar aquellas cosas que aumentan o favorecen la potencia de actuar del cuerpo" $(E I I I, 12,136)$ y "rehúye imaginar aquellas cosas que disminuyen o reprimen su potencia y la del cuerpo" ( $E$ III, 13, Corolario, 136) 10 "Los modos del pensar (modi cogitandi), como el amor, el deseo o cualesquiera de los designados con el nombre de afectos del ánimo (affectus animi), no se dan a menos que en el mismo individuo se dé la idea de la cosa amada, deseada, etc. En cambio, la idea se puede dar, aunque no se dé ningún otro modo del pensar" (E II, D 3, 78).

11 Pese a esta centralidad de lo cognoscitivo, es necesario anotar que para Spinoza en la Ética (a diferencia del Tratado breve) el querer, apetecer o desear determinada cosa no proviene de que realicemos un juicio de valor previo sobre el carácter bueno de esa cosa. No juzgamos una cosa como buena y por eso la deseamos, sino "por el contrario, juzgamos que algo es bueno porque nos esforzamos por ello, lo queremos, apetecemos y deseamos" (E III, 9, E, 133-134).

12 "... a las afecciones del cuerpo humano, cuyas ideas nos representan los cuerpos exteriores como presentes, las llamaremos imágenes de las cosas, aunque no reproducen las figuras de las cosas; y cuando el alma contempla desde esta perspectiva los cuerpos, diremos que los imagina" (EII, 17, 95). 
representarnos objetos externos a través de imágenes, ya sean percepciones, recuerdos o "imaginaciones". Para Spinoza, "la imagen de una cosa, considerada en sí sola, es la misma, ya se refiera al tiempo futuro o al pasado, ya al presente..." (E III, 18, 139). El primer orden del conocimiento regido por la imaginación brinda un conocimiento "confuso y mutilado", mediante el cual el alma humana no alcanza un conocimiento adecuado de sí misma, ni de su cuerpo, ni de los cuerpos exteriores (EII, 29, D, E, 101-102). Ello tendrá consecuencias importantes para el amor pasional regido por la imaginación.

\section{§4.1. Carácter asociativo de los afectos imaginativos}

Las imágenes que nos hacemos de los cuerpos exteriores son afecciones en nuestro propio cuerpo causadas por los "impactos" de "los vestigios de un cuerpo externo" ( $E$ II, 18, 95). Spinoza enfatiza que toda idea/imagen de un cuerpo externo implica tanto a la naturaleza del cuerpo afectado como a la naturaleza del cuerpo externo afectante $(E I, 16,93)$. La imaginación provee un conocimiento inadecuado y fragmentario porque las ideas 0 imágenes que nos formamos de un cuerpo externo dependen tanto del cuerpo externo que nos afecta como de nuestro propio cuerpo afectado. Más aún: "las ideas que tenemos de los cuerpos exteriores indican más la constitución de nuestro cuerpo que la naturaleza de los cuerpos exteriores" (EII, 16, C 2, 93).

De lo anterior, Spinoza deduce una característica muy importante de la imaginación y de los afectos que se derivan de ella: su carácter asociativo. Una de las principales manifestaciones de este carácter asociativo radica en que, si el alma fue afectada por dos cuerpos exteriores a la vez, luego, al percibir a uno, el alma recordará asociativamente al otro ${ }^{13}$. "Si el alma ha

13 "El alma imagina un cuerpo por el hecho de que el cuerpo humano es afectado y dispuesto por los vestigios de un cuerpo externo de la misma manera que es afectado cuando algunas de sus partes fueron impactadas por dicho cuerpo externo. Es así que (...) entonces el cuerpo fue dispuesto de forma que el alma imaginó dos cuerpos al mismo tiempo. Luego también después imaginará dos cuerpos a la vez; y, cuando el alma imagine uno de ellos, recordará inmediatamente al otro" (E II, 18, 95-96). 
sido una vez afectada por dos afectos al mismo tiempo, cuando después sea afectada por uno de ellos, lo será también por el otro" (E III, 14, 137). Spinoza fundamenta esa conclusión en que "las imaginaciones del alma indican los afectos de nuestro cuerpo más bien que la naturaleza de los cuerpos externos". Las imágenes son principalmente configuraciones del cuerpo afectado y de ello se infiere su carácter asociativo. "Percibir" algo es básicamente una configuración de nuestro cuerpo causada por un objeto externo. Si percibimos luego por separado dos cosas que antes percibimos juntas, nuestro cuerpo, al ser afectado por una de esas cosas, se configurará en la forma en que lo hizo al percibir las dos. En otras palabras, el carácter asociativo de la imaginación y de los afectos implica entonces que, si el alma ha percibido (ha sido afectada por) dos cuerpos a la vez, el imaginar después a uno de ellos traerá automáticamente el recuerdo del otro.

Del carácter asociativo de la imaginación se infiere el carácter asociativo de los afectos basados en ella. Spinoza lo explica en estos términos: si el alma es afectada por dos afectos simultáneamente, uno de los cuales es neutral en relación a su conato mientras que el otro lo aumenta o disminuye, entonces el afecto neutral también aumentará o disminuirá el conato "por accidente". "Por el solo hecho de que hemos contemplado una cosa con un afecto de alegría o de tristeza del que ella no es su causa eficiente, podemos amarla u odiarla" (E III, 15, C, 137). En principio es incluso posible amar una cosa que simplemente se asemeja a otra cosa que amamos u odiar a una cosa que se parece a otra que odiamos. Por mera asociación y semejanza con cosas amadas $u$ odiadas, objetos afectivamente neutrales puede ser causa de alegría y tristeza y, por ende, amor u odio ( $E$ III, 16, 138). “Cualquier cosa puede ser, por accidente, causa de alegría, tristeza o deseo" (E III, 15, 137).

En parte por su naturaleza asociativa, el amor pasional es un afecto ambivalente. Spinoza señala que es posible amar y odiar una misma cosa al mismo tiempo. El imaginar una semejanza entre una cosa que nos genera alegría y otra que nos genera tristeza puede ocasionar esa ambivalencia. "Si imaginamos que una cosa que suele afectarnos con un afecto de tristeza, tiene algo semejante a otra que suele afectamos con un afecto igual de alegría, la odiaremos y amaremos a la vez" (E III, 17, 138). Esta "disposición del alma" surgida de dos afectos contrapuestos es denominada por Spinoza 
fluctuación del ánimo. Otra de sus manifestaciones es el hastío o repugnancia que sucede cuando nuestra disposición corporal cambia después de haber disfrutado de una cosa deseada. El apetito por lo deseado se transforma es su opuesto luego de haberlo consumido: aquello que encontrábamos apetecible nos resulta ahora desagradable. Análogamente a lo que sucede con en el carácter asociativo de los afectos, el hastío tiene su origen en las configuraciones corporales propias de las afecciones de la imaginación ${ }^{14}$.

Como hemos visto, un objeto que nos es afectivamente neutral puede "cargarse" accidentalmente de deseo, alegría o tristeza si lo percibimos simultáneamente con otro que nos cause esos afectos. De este carácter asociativo Spinoza deduce otra conclusión importante acerca del amor mediado por la imaginación: una vez que poseemos un objeto deseado, por asociación afectiva desearemos que en el futuro se repitan las mismas circunstancias en las que lo poseímos. Afirma Spinoza: "Quien recuerda una cosa de la que gozó una vez, desea poseerla con las mismas circunstancias que cuando gozó de ella por primera vez", razón por la cual "si el amante descubre que falta una de esas circunstancias, se entristecerá" con añoranza ( $E$ III, 36, C y E, 150).

\section{§4.2. Carácter mimético de los afectos imaginativos}

Para Spinoza los afectos mediados por la imaginación tienen un carácter mimético o imitativo. Esto es, tendemos a ser afectados por los mismos afectos que imaginamos afectan a otros. "Por el solo hecho de imaginar que una cosa, que es semejante a nosotros y por la que no hemos sentido afecto alguno, está afectada por algún afecto, somos afectados por un afecto similar" (E III, 27, 144).

14 "(...) sucede muchísimas veces que, mientras disfrutamos de la cosa que apetecíamos, el cuerpo adquiere con esa fruición una nueva disposición, por la que es determinado de otra forma y se excitan en él otras imágenes de las cosas y, al mismo tiempo, el alma comienza a imaginar y a desear otras cosas. Por ejemplo, cuando imaginamos algo que suele deleitarnos con el sabor, deseamos disfrutar de ello, es decir, comerlo. Mas tan pronto como disfrutamos de él, el estómago se llena y el cuerpo se dispone de otra forma. De ahí que, si, una vez dispuesto ya el cuerpo de otra forma, es avivada la imagen de dicho alimento, porque está presente, y, por tanto, también el conato o deseo de comerlo, esa nueva disposición repugnará a este deseo o conato, y, en consecuencia, le será odiosa la presencia del alimento que apetecíamos. Y esto es lo que llamamos hastío o repugnancia" (E III, 59, E, 168-169). 
Spinoza afirma que este fenómeno constituye una "imitación de los afectos" y es intrínseco a la naturaleza humana. Los niños "ríen o lloran por el solo hecho de ver reír o llorar a otros; y cuanto ven hacer a los demás desean imitarlo al instante; y desean para ellos, en fin, todas las cosas con que imaginan que otros se deleitan" (E III, 32, E, 148). La imitación de los afectos de tristeza es la compasión. Pero cuando lo que se imita es deseos, Spinoza denomina al fenómeno "emulación", definida como "el deseo de una cosa, que se engendra en nosotros porque imaginamos que otros, semejantes a nosotros, tienen el mismo deseo" ( $E$ III, 27, E, 144). Además, imaginar que otro parecido a mí es afectado por alegría o tristeza genera en mí afectos dirigidos hacia la causa de la alegría o tristeza de ese otro. Se pueden despertar afectos hacia la causa imaginada de la alegría o tristeza de una cosa semejante a mí, incluso si antes no me unió ningún afecto hacia esa cosa ${ }^{15}$.

El carácter imitativo de los afectos tiene importantes consecuencias en el comportamiento de las personas. Los humanos tendemos a hacer aquello que imaginamos que nuestros semejantes aprueban y evitaremos hacer aquello que imaginamos que desaprueban, así como solemos amar aquello que otros aman y odiar aquello que otros odian ( $E$ III, 29, 146). Spinoza denomina "ambición" al esfuerzo por hacer aquello que los humanos aprueban y evitar hacer aquello que desaprueban. Este esfuerzo puede llegar a generar daño en uno mismo o en otro, lo cual constituye un peligro derivado de poner "tanto empeño en agradar al vulgo" (E III, 29, E, 146).

El carácter imitativo de los afectos también genera fluctuación del ánimo. Si yo imagino que alguien ama aquello que yo odio, mis afectos hacia el objeto odiado fluctuarán, y viceversa ${ }^{16}$. Del carácter mimético del deseo humano Spinoza deduce también que es sumamente difícil amar a alguien que es odiado por otros ( $E$ III, 31, C, 148). Asimismo, Spinoza infiere que los seres humanos nos esforzamos constantemente por lograr que otros amen

15 "Si imaginamos que alguien, al que no nos ha ligado ningún afecto, afecta de alegría a una cosa semejante a nosotros, seremos afectados de amor hacia él. En cambio, si imaginamos que la afecta de tristeza, seremos afectados de odio hacia el mismo" (E III, 27, C 1, 144).

16 "Si imaginamos que alguien ama o desea u odia algo que nosotros amamos deseamos $u$ odiamos, por eso mismo amaremos, etc. eso más constantemente. En cambio, si imaginamos que él aborrece lo que nosotros amamos, o al revés, sufriremos fluctuación del ánimo" (E III, 31, 147). 
lo que nosotros amamos y que odien lo que nosotros odiamos, lo cual no es más que una forma de ambición. Es un deseo natural humano el buscar que los otros compartan nuestras valoraciones y que todos vivan según nuestras opiniones. Dado que todos desean esto por igual, "por igual se estorban, y mientras todos quieren ser alabados o amados, todos se odian mutuamente" (E III, 31, C, 148).

Esta hostilidad generalizada no se limita a la ambición. El involucramiento de la imaginación y el carácter mimético del deseo tienen como consecuencia hostilidad. Cuando por emulación deseamos lo que otro desea y aquello deseado no puede ser poseído o gozado por varias personas a la vez, entonces se genera hostilidad: "Si imaginamos que alguien goza de una cosa que uno solo puede poseer, nos esforzaremos en lograr que no la posea" (E III, 32, 148). Spinoza descubre así que la misericordia y la compasión, pero también la envidia, la ambición y cierta hostilidad tienen en común el tener su origen en el carácter mimético de los afectos ${ }^{17}$.

\section{§4.3. Pasividad, inadecuación, discordia}

Como ya hemos mencionado, el amor descrito en la fenomenología crítica de los afectos que Spinoza esboza en el libro III de la Ética es un amor pasional, en otras palabras, es una alegría pasiva pues se basa en imágenes de causas exteriores. Esta pasividad es patente en la diversidad de afectos

17 Spinoza parece anticipar la teoría mimética del deseo de René Girard. En su genealogía especulativa de las sociedades primitivas, Girard afirma que una vez satisfechas las necesidades básicas, los seres humanos configuran su subjetividad (su "ser") imitando los deseos del Otro. Según Girard, de ello se sigue rivalidad, hostilidad y periódica violencia, que las sociedades "primitivas" expurgan mediante el violento sacrificio ritual de un chivo expiatorio. De acuerdo a Girard, el derecho moderno sería una forma de resolver disputas por medios racionales y neutrales, y de detener la violencia sacrificial ritual (Girard 1983). Algunos teóricos contemporáneos explican ciertas notables tendencias de las "redes sociales" (Facebook, Instagram, Twitter, etc.) en clave girardiana. De acuerdo a estos teóricos, el deseo imitativo, la competencia por status vía "likes" y la violencia colectiva contra individuos "juzgados" como "transgresores" en la llamada "cultura de la cancelación", serían fenómenos explicables como manifestaciones de deseo mimético y violencia ritual. En esa línea, las "redes sociales" y sus algoritmos promoverían rivalidad y también violencia mimética en la forma de espectáculos de sacrificio expiatorio tecnológicamente mediados. Al respecto véase Shullenberger 2020b; Shullenberger 2020a. 
contradictorios y fluctuantes a los cuales nos arriesgamos en el amor pasional. Como nos recuerda Gerszenzon (2016, 116-117), las ideas inadecuadas de la imaginación "pueden sucederse en un orden fortuito e incontrolable, dejándonos en un estado de dependencia de factores externos que no podemos dominar." Así, somos afectados por pasiones inconstantes, fluctuantes, opuestas o contradictorias: "Por donde resulta evidente que somos agitados de múltiples maneras por las causas exteriores y que, cual olas del mar agitadas por vientos contrarios, fluctuamos, sin conocer nuestra suerte ni nuestro destino" (E III, 59, E, 168).

Así, por ejemplo, imaginar la destrucción de lo amado genera tristeza, mientras que imaginar su conservación genera alegría ( $E$ III, 19, 140). Viceversa, imaginar la destrucción de lo odiado genera alegría, e imaginar su conservación, tristeza ( $E$ III, 20,141). Análogamente, si imaginamos que un objeto amado está afectado de alegría o tristeza, sentiremos esas afecciones nosotros mismos, según sea el caso ( $E$ III, 21, 141). Asimismo, sentiremos amor hacia aquello que imaginamos causa alegría a una cosa que amamos $y$, viceversa, sentiremos odio hacia aquello que imaginamos causa tristeza a una cosa que amamos $(E \mathrm{III}, 22,141)^{18}$. En cambio, si imaginamos que una cosa que odiamos es afectada de tristeza, nos alegraremos, pero si imaginamos que está afectada de alegría nos entristeceremos ( $E$ III, 23, 142). En esa línea, sentiremos amor por aquello que imaginamos que causa tristeza a lo que odiamos, mientras que seremos afectados por odio hacia aquello que imaginamos que causa alegría a lo que odiamos ( $E$ III, 24, 143). Este último odio es "la envidia, que no es, por tanto, sino el mismo odio, en cuanto que se considera que dispone al hombre de tal suerte que goza con el mal de otro y, al contrario, sufre con el bien de otro" ( $E$ III, 24, E, 143). Cabe anotar que aquellos afectos de alegría que gozan con el sufrimiento de una persona odiada son altamente inestables y generan considerable fluctuación en el ánimo. Esta fluctuación se origina porque esos afectos de alegría ante la desgracia, tristeza o destrucción ajenas se contraponen a los

18 Spinoza define a la compasión como "la tristeza surgida del daño de otro"y deja sin nombrar "la alegría que surge del bien de otro". Por su parte, aprecio es el "amor hacia aquel que ha hecho bien a otro" mientras que indignación es el "odio hacia aquel que ha hecho mal a otro" (E III, 22, E, 142). 
afectos de tristeza que se originan al imaginar que alguien que imagino parecido a mí está sufriendo (E III, 23, E, 142).

Por otro lado, Spinoza nos advierte que "el amor y el deseo pueden tener exceso" ( $E$ IV, 44, 213). El amor pasional puede degenerar en exceso y fijación. Para Spinoza el placer es alegría referida al cuerpo que, cuando "está acompañado de la idea de una causa exterior, es amor" (E IV, 44, D, 213). Dado que el placer es alegría referida al cuerpo y afecta a una parte del cuerpo más que a otras, "puede superar las demás acciones del cuerpo y adherirse pertinazmente al mismo, e impedir así que el cuerpo sea apto para ser afectado de otros muchos modos; $y$, por tanto, puede ser malo" ( $E I V, 43, \mathrm{D}, 214)$. Un amor-placer puede ocasionar que el cuerpo se quede fijado en él e inclusive puede bloquear la capacidad del cuerpo para recibir otras afecciones. Así, la lujuria, la ambición, la avaricia son formas de delirio, pues ocasionan percepciones alucinatorias del objeto deseado y son patológicas ( $E \mathrm{IV}, 44, \mathrm{E}, 214)$. Spinoza expresa especial preocupación sobre el amor sexual, "esto es, el deseo de engendrar que nace de la belleza" pues "se transforma fácilmente en odio, a menos - lo cual es peor - que sea una especie de delirio, y entonces es fomentado con la discordia más que con la concordia."19

Otra característica esencial del amor mediado por la imaginación es el esfuerzo por lograr que la cosa que amamos, cuando es una cosa semejante a nosotros, a su vez nos ame recíprocamente. "Cuando amamos una cosa semejante a nosotros, nos esforzamos, cuanto podemos, en lograr que ella nos ame a su vez" (E III, 33, 149). Cuanta más alegría imaginamos causar en la cosa amada, más alegría sentiremos nosotros: "tanto más nos gloriaremos" ( $E$ III, 34, 149). Sin embargo, en el amor pasional, el deseo de reciprocidad amorosa tiene su contracara en los celos ${ }^{20}$."Si alguien imagina

19 Ante esa preocupación, Spinoza propone que es posible que el matrimonio esté "acorde con la razón" si es que no se motiva por el deseo de engendrar "por la sola belleza", sino también por el amor de procrear hijos y de educarlos sabiamente; y si, además, "el amor de ambos, a saber, del varón y de la hembra, tiene por causa no sólo la belleza, sino también y principalmente la libertad de ánimo" (E IV, Apéndice, Cap. 20, 236).

20 Spinoza utiliza un lenguaje que parece alejarse de la frialdad del método geométrico y que se acerca más al de un amante despechado cuando describe los celos: "Y esta razón suele tener lugar en el amor hacia la hembra, puesto que quien imagina que la mujer que él 
que la cosa amada liga a otro a ella con un vínculo igual o más estrecho que aquel con que él solo la poseía, será afectado de odio hacia la misma cosa amada y de envidia hacia ese otro" ( $E$ III, 35, 149). Los celos suceden cuando los deseos de "ligarse" a la cosa amada y de sentir alegría por ser causa de su alegría se reprimen ante la imagen de la cosa amada ligada a otro. Estas imágenes generan odio hacia la cosa amada, así como odio y envidia hacia "el otro". Los celos son esta combinación de odio a la cosa amada sumado a la envidia dirigida al otro y constituyen otra manifestación de esa ambivalencia y fluctuación anímica a la cual nos somete el amor mediado por la imaginación. Cuanto más fuerte era el amor hacia la cosa amada y más fuerte se imagine el celoso que es el vínculo entre la cosa amada y el tercero, más fuerte será el odio hacia la cosa amada. El odio hacia la cosa amada se potencia además porque el celoso imagina que la cosa amada afecta de alegría a un objeto odiado y porque, además, el celoso "se ve forzado a unir la imagen de la cosa amada a la imagen de aquel que él odia" $(E \mathrm{III}, 35, \mathrm{E}, 150)^{21}$.

En conclusión, los afectos pasionales - fluctuantes, dependientes de lo exterior, miméticos, asociativos - generan hostilidad entre los seres humanos:

Un hombre, por ejemplo Pedro, puede ser causa de que Pablo se entristezca, por tener algo semejante a la cosa que Pablo odia o porque Pedro posee él sólo una cosa que también el mismo Pablo ama, o por otras causas. Y por eso, de ahí resultará que Pablo odie a Pedro y, por lo mismo, será fácil que Pedro tenga, a su vez, odio a Pablo, y que por ello mismo se esfuercen en hacerse daño el uno al otro, esto es, que sean contrarios entre sí. Ahora bien, el afecto de tristeza siempre es pasión. Luego los hombres, en cuanto que sufren los conflictos de afectos que son pasiones, pueden ser contrarios entre sí (E IV, 34, 204).

ama, se prostituye a otro, no sólo se entristecerá, porque su apetito es reprimido; sino que, además, siente aversión a ella, porque se ve forzado a unir la imagen de la cosa amada a las partes pudendas y a las excreciones de otro; a lo cual se añade, finalmente, que el celoso no es acogido por la cosa amada con el mismo semblante que solía mostrarle, por lo que también se entristece el amante (...)" (EIII, 35, 150).

21 Recordemos que imaginar que una cosa amada causa alegría a algo que odiamos puede hacer que odiemos a esa cosa amada y que, por ende, fluctúen nuestros afectos en relación con ella. 
Para Spinoza la vida de las pasiones no es coherente con una vida en concordia entre los seres humanos. Esto también tiene un fundamento cognoscitivo: las ideas inadecuadas de la imaginación hacen que los hombres "discrepen en naturaleza", pues estas ideas son de carácter excesivamente subjetivo ( $E$ IV, 34, E, 204). Como veremos, solo vivir y amar bajo la guía de la razón y de la ciencia intuitiva permite que los seres humanos concuerden en una vida en común pacífica, virtuosa y feliz.

\section{§5. Conclusiones: afectos activos y amor intelectual de Dios}

En el Tratado de la reforma del entendimiento y en el Tratado breve Spinoza nos recomienda alejarnos del amor inestable, ambivalente, finito y frágil, y nos exhorta a que nos concentremos en conocer y amar a Dios, el bien supremo que nos brindaría una alegría estable y permanente. En los libros IV y V de la Ética, Spinoza describe lo que sería este amor intelectual a Dios, asociándolo al tercer género del conocimiento. ¿Cómo entender este amor intelectual hacia Dios? Como hemos mencionado, algunas interpretaciones tradicionales han sugerido que el sabio de Spinoza sería un modelo de trascendencia al mundo material, de indiferencia frente a los seres humanos y de unión mística con Dios ${ }^{22}$. Como también hemos mencionado, estas interpretaciones entran en cierto conflicto con las premisas ontológicas y éticas del pensamiento de Spinoza. Dedicaremos estas conclusiones a indicar algunos posibles caminos para una comprensión del amor intelectual a Dios. Para ello, intentaremos esclarecer la relación entre la ciencia intuitiva del tercer género de conocimiento y el amor intelectual por Dios y analizaremos el rol de las ideas adecuadas para los afectos activos.

La filosofía del amor de Spinoza es un intento de esclarecer el funcionamiento de nuestros afectos para ganar, en la medida de lo posible, agencia y actividad y superar la pasividad. Spinoza aclara que el hecho de que el alma sea activa depende de que tenga un conocimiento adecuado. "Nuestra alma hace algunas cosas y padece otras, a saber, en la medida en que tiene ideas adecuadas, necesariamente hace algunas cosas, y en la medida 
en que tiene ideas inadecuadas, necesariamente padece algunas" ( $E$ III, 1, 127). Las acciones tienen su origen en ideas adecuadas, mientras que las pasiones tienen su origen en ideas inadecuadas ${ }^{23}$. El presupuesto de la filosofía de Spinoza que debemos tener en cuenta aquí es que la potencia y la actividad del alma "se define(n) por el sólo conocimiento" (EV, 20, E, 256).

La actividad y potencia del alma propician una libertad a la cual Spinoza aspira para la vida humana. Por ello, la filosofía de Spinoza propone una detallada fenomenología de los afectos que nos permita formular ideas claras y distintas sobre ellos: "Un afecto que es pasión, deja de ser pasión tan pronto como formamos de él una idea clara y distinta". Tendremos más control y acción sobre nuestros afectos —en la medida en que nos es posible- cuanto mejor los conozcamos. "Así, pues, un afecto está tanto más en nuestra potestad y el alma padece tanto menos a causa de él, cuanto mejor nos es conocido" ( $E V, 3$ y C, 247).

En la filosofía del amor de Spinoza, como en otros aspectos de su ética, de lo que se trata es de pasar de pasividad a la actividad, de la servidumbre de la pasión a la autonomía de la acción, mediante el conocimiento claro y distinto del funcionamiento causal de la Naturaleza de la cual somos parte. Este conocimiento nos permite, en la medida de lo posible, superar a los afectos basados en la imaginación y vivir un amor que no sea pasión sino acción guiada por la razón y por la libertad de ánimo. En el libro IV afirma: "A todas las acciones, a las que somos determinados por un afecto que es pasión, podemos ser determinados sin él, por la razón" (E IV, 59, 223). Spinoza pone el ejemplo de golpear: visto desde lo físico y visible, se trata de un movimiento de brazo y mano. Sin embargo, dos golpes aparentemente iguales pueden estar determinados de forma diferente: el uno determinado pasivamente por imágenes confusamente concebidas y por afectos pasionales como la ira y el odio, y el otro puede ser una acción guiada por la razón (E IV, 59, E, 224).

23 "Las acciones del alma surgen sólo de las ideas adecuadas; las pasiones, en cambio, sólo dependen de las inadecuadas" (E III, 3, 131). Spinoza es enfático sobre esto: "De aquí se sigue que el alma está sometida a tantas más pasiones cuantas más ideas inadecuadas tiene; $y$, al contrario, hace tantas más cosas cuantas más ideas adecuadas tiene" (E III, 1, C, 128). 
La comprensión correcta de nuestros afectos e imágenes nos lleva a relacionarlos con Dios. "El alma puede hacer que todas las afecciones del cuerpo o imágenes de las cosas se refieran a la idea de Dios" (EV, 14, 253). Todas las afecciones del cuerpo pueden ser esclarecidas formando conceptos claros y distintos, lo cual implica que el alma puede hacer que todas las afecciones se refieran a la idea de Dios. El autoconocimiento de mis afectos y de mí mismo en tanto cuerpo y alma me lleva a identificar a Dios como mi causa, lo cual genera alegría y amor a Dios ${ }^{24}$. El tercer género del conocimiento implica una alegría, gozo y tranquilidad de alma, "acompañada de la idea de sí mismo y acompañada también (...) de la idea de Dios como causa" ( $E$ $V, 32,262)$. En buena parte, de lo que se trata aquí es del conocimiento de que "el alma humana es una parte del entendimiento infinito de Dios" (E II, $11, \mathrm{C}, 86)$. El autoconocimiento del alma se relaciona al conocimiento de Dios y, ambos causan alegría y amor.

Esta alegría que experimenta el alma con el tercer género del conocimiento está relacionada también con la comprensión de que Dios es necesariamente eterno. El alma reconoce que "está en Dios y se concibe por Dios" (EV, 30, 260). Concebir a los cuerpos y al alma sub specie aeternitatis es entender que son modos de la Sustancia. Por ello, de acuerdo a Spinoza: "Cuanto más entendemos las cosas singulares, más entendemos a Dios" ( $E \mathrm{~V}, 24,258)$. En ese sentido, el amor intelectual de Dios no es una fusión mística con un Ser Trascendente y separado a través de un conocimiento esotérico. Por el contrario, en el conocimiento del tercer género el alma comprende su propia eternidad y su pertenencia a la eternidad misma de la Sustancia (Misrahi 2005, 58). Como menciona Spinoza en el libro Il de la Ética, el tercer género del conocimiento "procede de la idea adecuada de la esencia formal de algunos atributos de Dios al conocimiento adecuado de la esencia de las $\operatorname{cosas"~}^{\prime}(E I I, 40, E 2,108)$. Se trata de un conocimiento intuitivo de la relación entre el modo - la cosa finita, singular- y el atributo eterno de la Sustancia que le corresponde. De acuerdo a Misrahi, el conocimiento de esta

24 "Quien se conoce clara y distintamente a si mismo y a sus afectos, ama a Dios, y tanto más cuanto más se entiende a sí mismo y a sus afectos. (...). Quien se entiende clara y distintamente a sí mismo y a sus afectos, se alegra y ello acompañado de la idea de Dios. Luego, ama a Dios y (por el mismo motivo) tanto más cuanto más se entiende a sí mismo y a sus afectos" (EV, 15 , 253-254). 
relación brinda al alma una gran alegría, porque el alma reconoce su propia eternidad y actividad en la Sustancia. "El amor, aquí, es el nombre que toma la alegría de conocer cuando el objeto conocido es al mismo tiempo fuente de sentido y de permanencia" (Misrahi 2005, 59).

Vale la pena insistir en que, para Spinoza, Dios es la Sustancia o Naturaleza en el sentido de natura naturata, causa inmanente de la natura naturans. No se trata de un Dios trascendente creador. Recordar esto nos permite entender que el amor intelectual a Dios es también una aprehensión intuitiva de la pertenencia de todos los modos a la Totalidad infinita y eterna de la Naturaleza-Dios-Sustancia. El amor intelectual a Dios se deriva de esa aprehensión de la unidad de la totalidad y de la comprensión de que esa unidad fundamenta nuestro ser individual y nos confiere "una especie de eternidad" (que no debe confundirse con la eternidad de la imaginación o la memoria) ${ }^{25}$. El amor intelectual a Dios designa, en última instancia, "la relación existencial, intuitiva y reflexiva, del espíritu singular con la totalidad bien comprendida de la Naturaleza" (Misrahi 2005, 62) que constituye nuestra "salvación o felicidad o libertad" (EV, 36, 264).

Queda un importante rasgo del amor en la filosofía de Spinoza que vale la pena mencionar: el carácter ontológico del amor intelectual de Dios. Para Spinoza, el amor sería un rasgo ontológico de la Sustancia: “Dios se ama a sí mismo con un amor intelectual infinito" (E V, 35, 263). Este amor intelectual por medio del cual Dios se ama a sí mismo es además el mismo amor mediante el cual el alma humana ama a $\operatorname{Dios}^{26}$. Y si el amor que siente el alma humana por Dios es "parte del amor infinito con que Dios se ama sí mismo", entonces el amor en general debe ser entendido como un acto reflexivo de Dios sobre sí mismo. Inversa y concomitantemente, "el amor de

25 "Si atendemos a la opinión común de los hombres, veremos que ellos son sin duda conscientes de la eternidad de su alma; pero que ellos la confunden con la duración y la atribuyen a la imaginación, o sea a la memoria que creen que permanece después de la muerte" (EV, 34 , $\mathrm{E}, 263)$.

26 "El amor intelectual del alma a Dios es el mismo amor de Dios con el que Dios se ama a sí mismo, no en cuanto que es infinito, sino en cuanto que puede explicarse por la esencia del alma humana, considerada bajo una especie de eternidad. Es decir, que el amor intelectual del alma a Dios es parte del amor infinito con que Dios se ama a sí mismo" (EV, 36, 263). 
Dios a los hombres y el amor intelectual del alma a Dios es una y la misma cosa" (EV, 36, C, 265).

Para Spinoza en el libro V de la Ética, el amor es la alegría que siente el alma al autoconocerse, al entender a Dios como su causa y entenderse a sí misma como parte del entendimiento infinito de Dios. Por ello, el carácter reflexivo y autoamante de la Sustancia se revela a través del alma humana y de su actividad de amor que es, en última instancia, la actividad filosófica. De esto se concluye que el amor intelectual de Dios no es un amor recíproco entre dos entes separados - Dios y los hombres-, sino de dos direcciones que toma el amor como rasgo ontológico de la Totalidad (Misrahi 2005, 64).

En Spinoza, el amor intelectual de Dios y la aproximación al tercer género del conocimiento brindan un fundamento para una vida en sociedad virtuosa. Vivir bajo la guía de la razón hace que los seres humanos sean útiles entre sí. Bajo la guía de la razón los humanos concordamos, mientras que bajo las pasiones — subjetivas en tanto corporales - diferimos. La ayuda mutua, la solidaridad y la vida en común es posibilitada por la guía de la razón. Superadas en la medida de lo posible las pasiones, guiados por la razón bajo ideas claras y distintas, el hombre no es lobo para el hombre sino, por el contrario, "el hombre es un Dios para el hombre" (EV, 35, E, 206). El sumo bien es, entonces, vivir según la virtud, esto es, según la guía de la razón y conociendo a Dios. Cuando alguien alcanza la virtud busca que otros también la alcancen, sin celos, hostilidades ni desconfianzas. "El bien que apetece para sí todo aquel que persigue la virtud, lo deseará también para los demás hombres, y tanto más cuanto mayor conocimiento tenga de Dios."27

Cerramos reiterando una idea que hemos subrayado a través de este trabajo: el amor intelectual a Dios no implica un ascetismo, una "superación" de los objetos materiales ni tampoco una indiferencia hacia la vida de otros seres humanos. No se trata en Spinoza tanto de cuál es el objeto del amor sino de cómo amamos. Y cómo amamos está íntimamente relacionado a

27 “... cuanto mayor conocimiento de Dios implica la esencia del alma, mayor es también el deseo con que aquel que persigue la virtud, desea para otro el bien que desea para sí" (E IV, 37, 207). 
cómo conocemos: si nos aferramos a la imaginación, nuestro amor será pasional, de lo cual se derivará ambivalencia, fluctuación, inestabilidad y sufrimiento psicológico, así como disenso, hostilidad y conflicto a nivel colectivo. Por el contrario, tener un conocimiento claro y distinto sobre los objetos y sobre nuestros afectos nos brinda el fundamento para una vida afectiva activa y sana, controlando las pasiones y sabiendo que eliminarlas es imposible, en tanto somos seres corporales y finitos. Este conocimiento claro y distinto nos lleva al amor a Dios, verdadera fuente de un bien estable y constante ${ }^{28}$. Mediante su noción de amor y su fenomenología crítica de los afectos, Spinoza intenta realizar el difícil proyecto filosófico de las éticas eudaimonistas: relacionar la felicidad y libertad del individuo con su pertenencia virtuosa a la comunidad y englobar ambas en un autoconocimiento que es, en última instancia, el conocimiento de la Totalidad.

Recibido: $15 / 08 / 2021$

Aceptado: 06/11/2021

\section{Bibliografía}

Aristóteles, 1985. Ética Nicomáquea. Madrid: Gredos.

Bicknell, Jeanette, 1998. An Overlooked Aspect of Love in Spinoza's 'Ethics.' lyyun: The Jerusalem Philosophical Quarterly 47 (enero), 41-55.

DeBrabander, Firmin, 2007. Spinoza and the Stoics: Power, Politics and the Passions. Continuum Studies in Philosophy. London, New York: Continuum.

Epicuro, 2010. Epicurea. Edición de Hermann Usener. Cambridge: Cambridge University Press.

García Gual, Carlos, 2002. Epicuro. Madrid: Alianza Editorial.

28 "Por lo anterior concebimos fácilmente que es lo que el conocimiento claro y distinto, y ante todo aquel tercer género de conocimiento, cuyo fundamento es el mismo conocimiento de Dios, puede sobre los afectos, a saber: aunque no los suprime totalmente, en cuanto que son pasiones hace al menos que constituyan una parte mínima del alma. Por otra parte, engendra el amor hacia una cosa inmutable y eterna, del que somos realmente dueños; el cual, por tanto, no puede ser mancillado por ninguno de los vicios que se dan en el amor común, sino que puede ser siempre cada vez mayor y ocupar la mayor parte del alma y afectarla ampliamente" (EV, 20, E, 256). 
Gerszenzon, Lucía, 2016. El amor pasional en la Ética de Spinoza. Ideas. Revista de filosofía moderna y contemporánea 2 (3), 110-133.

Girard, René, 1983. La violencia y lo sagrado. Barcelona: Anagrama.

Hampshire, Stuart, 1982. Spinoza. Madrid: Alianza Editorial.

Hoyos, Inmaculada, 2012. La presencia del estoicismo en la filosofía de Spinoza: naturalismo estoico y spinoziano. Revista de Filosofía 37 (2), 69-89.

Jaquet, Chantal y otros, 2005. Préface. En: Spinoza, philosophe de l'amour, eds. Jaquet, Chantal y otros. Saint-Étienne: Publ. de l'Univ. de Saint-Étienne, 7-10.

Miller, Jon, 2015. Spinoza and the Stoics. Cambridge: Cambridge University Press.

Misrahi, Robert, 2005. 100 Mots Sur l'Ethique de Spinoza. Paris: Les empêcheurs de penser en rond.

Musonio Rufo; Epicteto, 1995. Tabla de Cebes; Disertaciones - Fragmentos Menores; Manual - Fragmentos. Madrid: Gredos.

Nussbaum, Martha Craven, 2012. La terapia del deseo: teoría y práctica en la ética helenística. Barcelona: Paidós.

Platón, 2016a. Fedón, Fedro. Madrid: Alianza Editorial.

Platón, 2016b. El banquete. Madrid: Alianza.

Rorty, Amélie Oksenberg, 2009. Spinoza on the Pathos of Idolatrous Love and the Hilarity of True Love. En: Feminist Interpretations of Benedict Spinoza, ed. Moira Gatens. Pennsylvania: Pennsylvania State University Press, 65-85.

Shullenberger, Geoff, 2020a. "Human Sacrifice and the Digital Business Model." Tablet Magazine. https://www.tabletmag.com/sections/science/articles/sacrificialgames-cancel-culture. Consultado 15 de agosto 2021.

Shullenberger, Geoff, 2020b. "Control Societies with Sacrificial Characteristics." Outsider Theory. https://outsidertheory.com/control-societies-with-sacrificialcharacteristics/. Consultado 15 de agosto 2021.

Spinoza, Benedictus de, 1988. Tratado de la reforma del entendimiento; Principios de filosofía de Descartes; Pensamientos metafísicos. Madrid: Alianza Editorial.

Spinoza, Benedictus de, 2000. Ética demostrada según el orden geométrico. Madrid: Trotta.

Spinoza, Benedictus de, 1990. Tratado Breve. Madrid: Alianza Editorial.

Spinoza, Benedictus de, 2021. Ethica More Geometrico Demonstrata. http://www.ethicadb.org/plan.php?lanid=0\&lg=es.

Vardoulakis, Dimitris, 2020. Spinoza, the Epicurean: Authority and Utility in Materialism. Spinoza Studies. Edinburgh: Edinburgh University Press. 